\title{
AMENDMENTS
}

\section{Publisher Correction: Stresses in thin sheets at fluid interfaces}

Deepak Kumar, Thomas P. Russell(10, Benny Davidovitch and Narayanan Menon (D)

Correction to: Nature Materials https://doi.org/10.1038/s41563-020-0640-9, published online 16 April 2020.

In the version of this Correspondence originally published, the double-headed vertical arrow within the block in Fig. $3 \mathrm{~b}$ was incorrectly labelled $\frac{\gamma_{\text {sv }}}{Y} W$; it should have been labelled $\frac{\gamma_{\mathrm{sv}}}{E}$. This has now been corrected.

Published online: 23 April 2020

https://doi.org/10.1038/s41563-020-0691-y

() Springer Nature Limited 2020

\section{Publisher Correction: Interlayer excitons: Moiré or not}

Alexander Tartakovskii D

Correction to: Nature Materials https://doi.org/10.1038/s41563-020-0693-9, published online 27 May 2020.

In the version of this News \& Views originally published, the two 'Interlayer exitation' labels in Fig. 1 were incorrect; they should have read 'Interlayer exciton'. This has now been corrected in the online versions of this News \& Views.

Published online: 1 June 2020

https://doi.org/10.1038/s41563-020-0718-4

๑) Springer Nature Limited 2020 